\title{
The perspectives of wine industry development in the Samara region
}

\author{
V.V. Bakharev, P.A. Chaldaev*, S.S. Malishkin, D.V. Zenkova, P.A. Feoktistov, and D.E. Bykov \\ Samara State Technical University, 443100 Samara, Molodogvardeyskaya str., 244, Russia
}

\begin{abstract}
The article discusses the perspectives of wine industry development in the Samara region. It represents a 5-year (2014-2018) assessment of quality indicators involving 16 commercial varieties of grape, cultivated in the Samara region. The grape quality was assessed based on physical and chemical indicators of stum and dry table wine. The research showed significant fluctuations in physical and chemical indicators depending on the year, connected with unstable climatic conditions of growing. The data obtained after the analysis of stum and wine shows that climatic conditions in the Samara region allow for growing and processing not only early and early to medium varieties but also obtaining good results for medium and medium-late grape. The research shows that the development of the wine industry in the Samara region looks promising with the application of special techniques.
\end{abstract}

\section{Introduction}

Grape is one of the most valuable fruits in the world. It is consumed both in fresh and processed form. About 50$75 \%$ of grape is processed into juice or wine [1]. According to the International Organization of Vine and Wine (OIV), the production of wine is decreasing in the Old World and increasing in the New World [2]. This growth is also achieved due to the expansion of winemaking further north. This is facilitated by the development of grape varieties that are resistant to cold and diseases [3].

The quality and typicality of wines significantly depend on natural factors, mainly temperature [4]. As a rule, the wines from northern regions have higher acidity and lower content of alcohol in comparison with southern wines [5].

The vegetation of most European and Asian grape varieties starts when the temperature of air and soil reaches $8-12{ }^{\circ} \mathrm{C}$ and finishes in autumn at the same temperature. That's why the average daily temperature of $10{ }^{\circ} \mathrm{C}$ is accepted as a biological zero for grape. One of the most important characteristics of growing conditions is the sum of active temperatures that is calculated by summing the values of all temperatures higher than $10^{\circ} \mathrm{C}$ during vegetation.

In the northern regions, the minimal sum of active temperatures for growing grape should be $2500{ }^{\circ} \mathrm{C}$ for early varieties, $2800{ }^{\circ} \mathrm{C}$ for medium varieties and 3300 ${ }^{\circ} \mathrm{C}$ for late varieties [6].

The Samara region is not a traditional winemaking area. However, in recent years the commercial varieties of grape have been grown here not only by individual gardeners but farm enterprises. The Samara region is characterized by a temperate continental climate. It has sharp temperature contrasts, the lack of humidity, intensive winds and enhanced exposure to the sun. Precipitation is uneven both in terms of years and different periods of a year. Despite that wine growing in this region is risky and involves protective covering, there are all main factors allowing for cultivating both table and commercial grape varieties at an industrial scale.

The frostless season is $135-160$ days while the sum of active temperatures can reach $2600-2800{ }^{\circ} \mathrm{C}$ and more $[7,8]$. Therefore, it is important to understand the perspectives of growing and processing the commercial varieties of grape cultivated in the Samara region to produce wine.

\section{Objects and methods of research}

The research involved commercial varieties of grape grown in the vicinity of Olgino village in the Bezenchukskiy region $\left(52^{\circ} 51^{\prime} 32^{\prime \prime N} 49^{\circ} 09^{\prime} 35^{\prime \prime} \mathrm{E}\right)$, as well

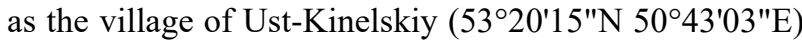
in the Samara region (2014-2018). The grape was picked manually in the presumed period of ripeness. Below is the overview of varieties involved.

Cristall (Seyve Villard 12-375 x Alfeld 100) is an early variety (110-115 days, 20-30 August) with increased resistance to low temperatures (up to $-35{ }^{\circ} \mathrm{C}$ ) and immunity to most fungal diseases. It is a highyielding grape for dry Sherry wines.

Platovskiy (Zala Dend x Podarok Magaracha, bred by All-Russian National Research Institute of Viticulture and Winemaking named after Ya.I. Potapenko) is an early and winter-resistant variety (110-115 days, 20-30 August), good for dry and dessert wines.

\footnotetext{
* Corresponding author: pal-sanych@mail.ru
} 
Sauvignon blanc (Traminer $\mathrm{x}$ Chenin blanc) is a variety that has the maturation period of 135 days (the end of September - the beginning of October), resistant to cold climate. One of the most common white grape varieties in the world.

Pinot Gris (Pino Meunier x Traminer) - the period between the bud break and maturation is 130 days for production of table and sparkling wines and 150 days for dessert wines. The sum of active temperatures accounts for $2600-2800{ }^{\circ} \mathrm{C}$ and the first ripe grapes appear in the first part of September. The variety has high resistance to cold (up to $-20^{\circ} \mathrm{C}$ ).

Bianca (Shasla Buvie x Villard blanc, Hungary) is an early variety (120 days) that can stay on the vine for a long time, accumulating sugar, with a small decrease in acidity. This allows for producing dry, semisweet, fortified and dessert wines depending on the harvest time. The variety has increased cold resistance and can be grown without covering.

Riton (Villard blanc $\mathrm{x}$ Riesling, Moldova) - the maturation period is 135-140 days (the middle of September), resistance to cold up to $-27^{\circ} \mathrm{C}$.

Citronniy Magaracha (Madlen Anjevin x Novoukrainskiy ranniy, Crimea) - the maturation period is 120-130 days. The variety has increased resistance to gray mold, mildew, and oidium, as well as cold up to $25{ }^{\circ} \mathrm{C}$.

Merlot (Cabernet Franc x Magdeleine Noir de Charentes) is a late variety (the end of September - the beginning of October). The period between bud break and maturation is 152 days for table wines and 164 days for dessert wines.

Pinot noir (Pinot Meunier $\mathrm{x}$ Traminer) - the maturation period is $140-150$ days (middle to end of September). The variety has low yield and low resistance to cold $\left(-25-30{ }^{\circ} \mathrm{C}\right)$ and the majority of viticides and diseases.

Livadiyskiy cherniy (Megru Vagaas x Magarach 124-66-26) is a middle-late variety (130-135 days) with high yield and resistance to mildew, gray mold, oidium and cold up to $-25^{\circ} \mathrm{C}$.

Cymlyansky cherniy is an early-middle variety (130135 days, end of August, the beginning of September) that is not resistant to diseases. Especially affected by mildew and needs a full set of measures for protection against fungal diseases. The variety requires covering for winter.

Saperavy severniy (Severniy x Saperavy, bred by AllRussian National Research Institute of Viticulture and Winemaking named after Ya.I. Potapenko) is a middlelate variety (140-145 days, the end of September) with an average resistance to diseases. The variety has high resistance to gray mold, and mildew, as well as cold.

Levokumskiy (bred based on Vitis Labrusca) is an early-medium variety (120-140 days) with high yield and resistance to cold up to $-27^{\circ} \mathrm{C}$.

Rubin Golodrygy (Rubinoviy Magaracha X Magarach 6-68-27) is a medium to late variety (135-145 days, middle-end of September) that is stable to grapelouse, mildew, oidium, gray mold, and temperatures up to $-26{ }^{\circ} \mathrm{C}$.
Gurzufskiy rozoviy (Muskata VIRa $\mathrm{x}$ Magarach) is an early variety (130 days, end of August - the beginning of September) with high yield and resistance to temperatures up to $-27^{\circ} \mathrm{C}$.

Cabernet Sauvignon (Cabernet Franc x Sauvignon) is a medium to late variety (end of September beginning of October). The maturation period is 143 days for table wines and 165 days for dessert wines). The variety is resistant to temperatures up to $-23^{\circ} \mathrm{C}$ ) and fungal diseases.

The grape quality was assessed based on the following physical and chemical properties of stum: total sugar (measured by the refractometric method) [9], the mass fraction of titratable acids [10].

Dry table wines were obtained from some grape varieties and analyzed. The grape processing was done in semi-industrial conditions in the laboratory of fermenting processes of the faculty of food manufacturing in Samara State Technical University.

The separation of stems was done with the help of DMAI manual crusher with grape stalk remover (Grifo, Italy). The stum was obtained from must with the help of $60 \mathrm{~K}$ basket press (VORAN Maschinen $\mathrm{GmbH}$, Austria). Sulfur dioxide was then added to the stum with the ratio of $50 \mathrm{mg} / \mathrm{l}$. The stum, which was cooled at $10-12{ }^{\circ} \mathrm{C}$, was clarified by settling it for $10-12$ hours. Then a sample of the stum was analyzed and sent for fermentation in a stainless-steel reservoir.

The air temperature in the fermentation reservoir was maintained at the level of $14 \pm 1{ }^{\circ} \mathrm{C}$. The fermentation was controlled by analyzing the temperature and density of the fermenting stum. Intensive fermenting lasted for 6-7 days and the temperature of the stum increased to $21-22{ }^{\circ} \mathrm{C}$.

In the case of red grape varieties, the fermentation was done in must with a hat. Sulfur dioxide at the ratio of $50 \mathrm{mg} / \mathrm{kg}$ was preliminary added to the must. The temperature of fermenting was $28-30{ }^{\circ} \mathrm{C}$ while the period of fermentation was 4-7 days. The fermented must was pressed with the basket press and sent for further fermenting to a stainless-steel reservoir.

The dry active wine yeast was used for stum and must fermenting based on the ratio of $20 \mathrm{~g}$ per 100 liters of stum (100 kg of must).

In the case of low sugar content, the stum or must were enriched by adding concentrated stum to increase the fraction of ethanol, but not more than $4 \%$.

After fermentation and self-clarification (15-20 days) the obtained wine was racked off, sulfated with $25 \mathrm{mg}$ of sulfur dioxide per liter and left for storing in stainless steel reservoirs at the temperature of $14{ }^{\circ} \mathrm{C}$ without oxygen. After 2 months of storing the wine was racked again and sulfur dioxide was added with the ratio of 25 $\mathrm{mg} / \mathrm{l}$. Then, a sample was taken for analysis.

The quality of wine was analysed based on the following indicators: alcohol by volume [11], mass fraction of sugar, based on Bertrand method [12], mass fraction of titratable acid [10], mass fraction of volatile acid [13], mass fraction of total dry extract [14], mass fraction of phenolic substances [15]. 


\section{Results}

The results of stum analysis are present in table 1 .

The analysis of 5-year data showed significant fluctuations of physical and chemical indicators depending on the year, connected with unstable climatic conditions of growing.

In some years (especially 2017) the grape didn't accumulate enough sugar and had a high mass fraction of titratable acid due to abundant precipitation and low temperatures during maturation.

The majority of studied grape varieties is suitable for strong beverages, as well as sparkling and table wines based on stum characteristics.

Although grapes of some varieties had high amounts of sugar in some years, they are not suitable for dessert, liqueur and fortified wines due to the high acidity of stum.

Table 1. The results of stum analisys.

\begin{tabular}{|c|c|c|c|}
\hline Grape variety & Year & $\begin{array}{l}\text { The mass fraction of sugar, } \\
\qquad \mathrm{g} / 100 \mathrm{~cm}^{3}\end{array}$ & $\begin{array}{l}\text { The mass fraction of titratable } \\
\text { acid equivalent to tartaric acid, } \\
\qquad \mathrm{g} / \mathrm{dm}^{3}\end{array}$ \\
\hline \multicolumn{4}{|c|}{ White grape varieties } \\
\hline Cristall & 2014 & 20.0 & 6.8 \\
\hline \multirow{2}{*}{ Platovskiy } & 2014 & 19.6 & 7.4 \\
\hline & 2015 & 17.1 & 6.7 \\
\hline Sauvignon blanc & 2016 & 19.1 & 7.6 \\
\hline Pinot gris & 2016 & 17.8 & 8.9 \\
\hline Bianca & 2016 & 23.1 & 7.9 \\
\hline Riton & 2016 & 17.8 & 6.7 \\
\hline \multirow{5}{*}{ Citronniy magaracha } & 2014 & 18.4 & 7.7 \\
\hline & 2015 & 17.8 & 7.4 \\
\hline & 2016 & 19.8 & 6.9 \\
\hline & 2017 & 14.9 & 12.5 \\
\hline & 2018 & 18.0 & 10.7 \\
\hline \multicolumn{4}{|c|}{ Red grape varieties } \\
\hline \multirow{4}{*}{ Merlot } & 2015 & 20.5 & 5.6 \\
\hline & 2016 & 19.4 & 7.2 \\
\hline & 2017 & 15.6 & 14.8 \\
\hline & 2018 & 21.7 & 9.2 \\
\hline \multirow{3}{*}{ Pinot noir } & 2015 & 18.0 & 5.9 \\
\hline & 2016 & 13.8 & 11.5 \\
\hline & 2018 & 22.5 & 8.6 \\
\hline \multirow{3}{*}{ Livadiyskiy cherniy } & 2015 & 16.8 & 7.0 \\
\hline & 2016 & 18.6 & 6.2 \\
\hline & 2017 & 16.1 & 11.0 \\
\hline \multirow{3}{*}{ Cymlyanskiy cherniy } & 2016 & 16.7 & 8.4 \\
\hline & 2017 & 14.4 & 15.3 \\
\hline & 2018 & 18.0 & 11.6 \\
\hline \multirow{2}{*}{ Saperavy severniy } & 2016 & 18.8 & 8.7 \\
\hline & 2018 & 16.1 & 9.0 \\
\hline \multirow{2}{*}{ Levokumskiy } & 2016 & 16.7 & 6.6 \\
\hline & 2017 & 15.1 & 11.3 \\
\hline \multirow{2}{*}{ Rubin Golodrigy } & 2016 & 17.6 & 12.1 \\
\hline & 2017 & 9.5 & 16.5 \\
\hline \multirow{2}{*}{ Gurzufskiy rozoviy } & 2016 & 18.6 & 8.3 \\
\hline & 2018 & 24.7 & 9.9 \\
\hline \multirow{3}{*}{ Cabernet Sauvignon } & 2016 & 16.5 & 13.2 \\
\hline & 2017 & 16.0 & 12.9 \\
\hline & 2018 & 21.3 & 6.9 \\
\hline \multicolumn{2}{|l|}{ Standard requirements [16] } & Not less than 16.0 & Not rated \\
\hline \multicolumn{2}{|c|}{$\begin{array}{l}\text { Optimal parameters [17]: } \\
\text { - for strong beverages (like brandy) } \\
\text { - for sparkling wines } \\
\text { - for dry, semi-dry and semi-sweet wines } \\
\text { - for strong wines } \\
\text { - for dessert and liqueur wines }\end{array}$} & $\begin{array}{l}\text { Not less than } 16.0 \\
\quad 17.0-20.0 \\
17.0-22.0 \\
\text { Not less than } 20.0 \\
\text { Not less than } 22.0\end{array}$ & $\begin{array}{l}8-12 \\
7-11 \\
5-9 \\
5-8 \\
4-7\end{array}$ \\
\hline
\end{tabular}


The results of dry table wine analysis are present in table 2 .

The data showed that all white table wines matched the standard requirements based on main quality indicators.
Some red table wines did not match the requirements based on the content of extractive substances and had high acidity and low content of phenolic substances.

Table 2. The results of dry table wine analisys.

\begin{tabular}{|c|c|c|c|c|c|c|c|}
\hline 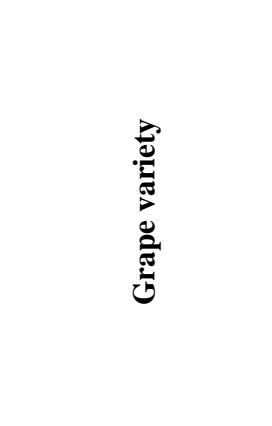 & $\stackrel{\bar{\varpi}}{\grave{\nu}}$ & 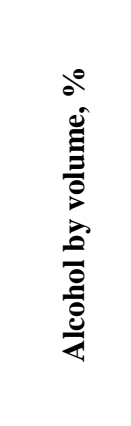 & 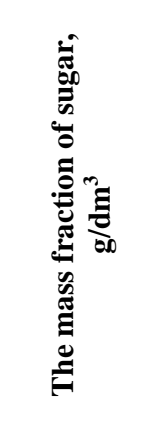 & 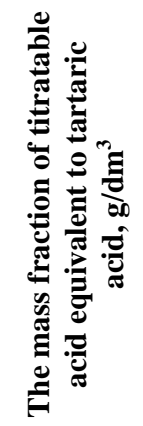 & 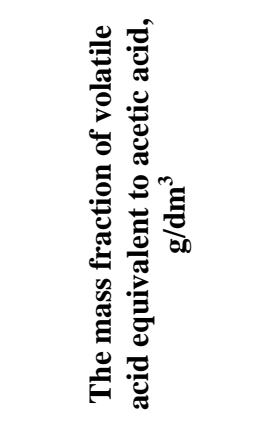 & 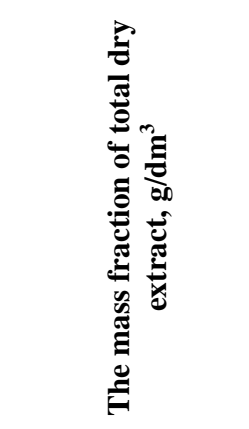 & 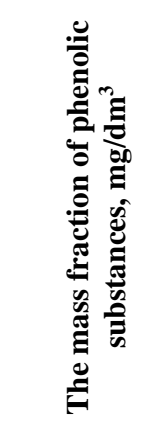 \\
\hline \multicolumn{8}{|c|}{ White wine } \\
\hline Cristall & 2014 & 9.7 & 1.9 & 5.6 & 0.27 & 20.0 & 675 \\
\hline \multirow{2}{*}{ Platovskiy } & 2014 & 12.6 & 1.9 & 6.0 & 0.18 & 21.2 & 621 \\
\hline & 2015 & 11.3 & 1.6 & 5.8 & 0.20 & 20.4 & 162 \\
\hline \multirow{5}{*}{$\begin{array}{l}\text { Citronniy } \\
\text { magaracha }\end{array}$} & 2014 & 9.6 & 2.0 & 6.0 & 0.24 & 19.8 & 594 \\
\hline & 2015 & 10.2 & 2.3 & 7.5 & 0.35 & 23.5 & 162 \\
\hline & 2016 & 12.6 & 2.1 & 5.5 & 0.20 & 25.9 & 189 \\
\hline & 2017 & 10.8 & 1.5 & 9.9 & 0.19 & 19.9 & 256 \\
\hline & 2018 & 11.2 & 1.2 & 6.1 & 0.40 & 16.0 & 391 \\
\hline \multicolumn{8}{|c|}{ Red wine } \\
\hline \multirow{3}{*}{ Merlot } & 2015 & 11.0 & 3.7 & 5.9 & 0.25 & 20.3 & 2072 \\
\hline & 2016 & 11.5 & 3.3 & 6.0 & 0.26 & 20.6 & 1890 \\
\hline & 2018 & 11.0 & 1.0 & 5.7 & 0.33 & 16.2 & 2700 \\
\hline \multirow{2}{*}{ Pinot noir } & 2015 & 10.6 & 1.8 & 6.1 & 0.07 & 19.2 & 459 \\
\hline & 2016 & 11.3 & 2.2 & 10.0 & 0.73 & 17.4 & 1188 \\
\hline \multirow{3}{*}{ Livadiyskiy cherniy } & 2015 & 10.1 & 2.9 & 6.6 & 0.13 & 21.9 & 3268 \\
\hline & 2016 & 11.3 & 3.4 & 5.3 & 0.20 & 21.4 & 2754 \\
\hline & 2017 & 9.6 & 3.3 & 10.7 & 0.40 & 18.0 & 699 \\
\hline Saperavy severniy & 2018 & 10.4 & 1.0 & 7.0 & 0.33 & 17.7 & 5940 \\
\hline \multirow{2}{*}{$\begin{array}{c}\text { Cabernet } \\
\text { Sauvignon }\end{array}$} & 2017 & 9.4 & 2.1 & 11.5 & 0.26 & 16.8 & 756 \\
\hline & 2018 & 10.9 & 1.5 & 6.5 & 0.13 & 18.2 & 3240 \\
\hline \multicolumn{2}{|c|}{$\begin{array}{l}\text { Standard requirements [18]: } \\
\text { - for white wines } \\
\text { - for red wines }\end{array}$} & $8.5-15.0$ & $\begin{array}{l}\text { Not more } \\
\text { than } 4.0\end{array}$ & $\begin{array}{l}\text { Not less } \\
\text { than } 3.5\end{array}$ & $\begin{array}{l}\text { Not more than } 1.1 \\
\text { Not more than } 1.2\end{array}$ & $\begin{array}{l}\text { Not less than } 16.0 \\
\text { Not less than } 18.0\end{array}$ & $\begin{array}{c}150-1500^{*} \\
1000-5000^{*}\end{array}$ \\
\hline
\end{tabular}

\section{Conclusion}

The analysis of data based on the obtained stum and wine shows that climatic conditions in the Samara region allow for growing and processing not only early and early-medium varieties, but also obtaining good results for medium and medium-late grape. Summarizing the 5year research, it is possible to say that the main problem of the wine industry in the Samara region is the instability of commercial grape quality from year to year.

However, using special techniques, like stum enrichment and the reduction of acid in wine, it is possible to get wine products matching normative requirements. This creates the base for further research in the validation and development of winemaking technology. It is also possible to say that industrial winemaking in the Samara region has good perspectives for further development.

\section{References}

1. C. Venkitasamy, L. Zhao, R. Zhang, Z. Pan, Integrated Processing Technologies for Food and Agricultural By-Products 6 (Academic Press, 2019)

2. L. Benoît, A. William, H. Lindsey, L.F. Adrienne, M.W. Marianne, Case Studies in the Wine Industry 2 (Woodhead Publishing, 2019)

3. W.F. Lee, W.C. Gartner, Wine Economics and Policy 4, 35-44 (2015) 
4. M. Tengzhen, K. Chen, H. Yan, H. Shunyu, B. Yang, Red Wine Technology 24 (Academic Press, 2019)

5. B. Kemp, K. Pedneault, G. Pickering, K. Usher, J. Willwerth, Red Wine Technology 23 (Academic Press, 2019)

6. A.A. Zarmayev, Wine growing and basic technologies for initial grape processing (KolosS, Moscow, 2011) (in Russian)

7. P.A. Chaldaev, Magarach Winegrowing and making 3, 91-92 (2018) (in Russian)

8. B.G. Sherstyukov, The climate of the Samara region and its characteristics for climate-dependent economy sectors (Privolzhskoye UGMS, Samara, 2006) (in Russian)

9. GOST 27198-87. Fresh grape. The methods for the determination of the mass fraction of sugar

10. GOST 32114-2013. Alcoholic products and materials for their manufacturing. The methods for the determination of the mass fraction of titratable acid

11. GOST 32095-2013. Alcoholic products and materials for their manufacturing. The methods for the determination of the alcohol by volume
12. GOST 13192-73. Wines, wine bases and brandy. The method for sugar determination

13. GOST 32001-2012. Alcoholic products and materials for their manufacturing. The methods for the determination of the mass fraction of volatile acid

14. GOST 32000-2012. Alcoholic products and materials for their manufacturing. The methods for the determination of the mass fraction of total dry extract

15. V.G. Gerzhikova, The method for technical and chemical control in wine making (Tavrida, Simferopol, 2009) (in Russian)

16. GOST 31782-2012. Manual and machine harvested fresh grape for industrial processing. Technical specifications

17. V.T. Kosyura, L.V. Donchenko, V.D. Nadykta, Wine making basics (Yurayt, Moscow, 2019) (in Russian)

18. GOST 32030-2013. Table wines and wine base. Technical specifications 